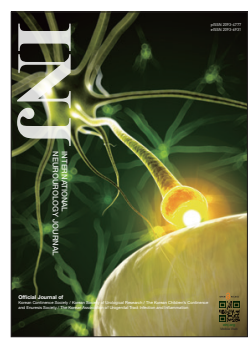

\title{
Cognitive Function and Urologic Medications for Lower Urinary Tract Symptoms
}

\author{
Yeon Joo Kim¹, Bum Sik Tae ${ }^{2}$, Jae Hyun Bae ${ }^{2}$ \\ ${ }^{1}$ Department of Urology, Daegu Fatima Hospital, Daegu, Korea \\ ${ }^{2}$ Department of Urology, Korea University Ansan Hospital, Korea University College of Medicine, Ansan, Korea
}

\begin{abstract}
Special considerations should be made when selecting medications for the treatment of lower urinary tract symptoms (LUTS) in older patients especially those over 65 years old. This review summarizes the relationship between current treatments for LUTS and cognitive impairment. Although the recently reported association between dementia and tamsulosin is debatable, the effects of $a$-blockers and pharmacokinetics are not reported in this context. Five-alpha reductase inhibitors appear to affect mood. However, the association between the development of dementia and cognitive impairment is unlikely. Anticholinergic agents, other than trospium, fesoterodine, and imdafenacin have a relatively high distribution in the central nervous system. In particular, oxybutynin is reported to cause cognitive impairment. Several animal studies on the blood-brain barrier permeability of oxybutynin support this. Therefore, care must be taken when they are used in older patients (65 years and older). Beta-3 agonists are an alternative to, or may be used in combination with, anticholinergic drugs for patients with an overactive bladder (OAB). Several phase 2 and 3 clinical studies report high tolerability and efficacy, making them relatively safe for OAB treatment. However, there is a possibility that cognitive function may be affected; thus, long-term study data are required. We have reviewed studies investigating the correlation of urologic medications with cognitive dysfunction and have provided an overview of drug selection, as well as other considerations in older patients (65 years and older) with LUTS. This narrative review has focused primarily on articles indexed in PubMed, Google Scholar, Scopus, and Embase databases. No formal search strategy was used, and no meta-analysis of data was performed.
\end{abstract}

Keywords: Adrenergic alpha-antagonists; 5-Alpha reductase inhibitors; Cholinergic antagonists; Adrenergic beta-3 agonists; Cognitive dysfunction; Dementia

- Grant/Fund Support: This work was supported by a National Research Foundation of Korea (NRF) grant funded by the Korea government

(MSIT) (No. 2019R1F1A1058422) and a Korea university grant.

- Conflict of Interest: No potential conflict of interest relevant to this article was reported.

\section{INTRODUCTION}

Announced by the Korea National Statistical Office in 2019, approximately $14.9 \%$ of the Korean population is 65 years of age or older. The proportion of people over 65 years of age continues to increase and is predicted to account for $25 \%$ of the total population by 2030 [1]. The prevalence and severity of lower urinary tract symptoms (LUTS) are known to increase with age; in addition, the use of drugs to treat LUTS is expected to increase [2-6].

Polymorbidity and polypharmacy are more common among the older than the young populations. In a study using national

Corresponding author: Jae Hyun Bae (iD https://orcid.org/0000-0001-9862-3545 Department of Urology, Korea University Ansan Hospital, Korea University College of Medicine, 123 Jeokgeum-ro, Danwon-gu, Ansan 15355, Korea E-mail: urobae@korea.ac.kr

Submitted: March 11, 2020 / Accepted after revision: April 8, 2020 
health insurance data from 2010 to 2011 in Korea, the reported prevalence of polypharmacy (taking 6 or more drugs) for patients over 65 years was $86.4 \%$ [7]. However, older people are often excluded from clinical studies owing to their age, and there is little evidence to support the safety and effectiveness of drugs in older people [8-10]. Polypharmacy has been reported to increase the probability of drug-drug interaction and to be associated with increased mortality, as well as side effects such as cognitive impairment and falls [11-13].

Therefore, clinicians must consider the potential drug-drug interactions and the decreased body function in old age when prescribing drugs to older patients $[14,15]$.

The Fit fOR The Aged (FORTA) classification was introduced in 2008 with the aim of guiding physicians in their screening process for inappropriate or harmful medications and drug omissions in older patients in an everyday clinical setting [16]. The LUTS-FORTA 2014 study on urological medicine was reported [14]. Consensus was achieved through expert ratings, but the theoretical background is weak owing to insufficient pharmacokinetic evidence.

Although numerous studies have linked cognitive impairment and LUTS drugs, there is no consolidated evidence. Our review compiles scattered reports of this correlation between cognitive impairment and LUTS drugs to present an overall picture, so that treatment selection can be guided in the future.

\section{MATERIALS AND METHODS}

For this review, literature reports over 15 years (from January 1994 to January 2020) were searched by using the PubMed, Google Scholar, Scopus, and Embase databases. Keywords, such as "cognition," "cognitive impairment," "dementia," and "Alzheimer's disease," were used to find studies related to cognitive impairment and dementia. In addition, searches using the keywords "adrenergic alpha-antagonists," "5-alpha reductase inhibitors," "cholinergic antagonists," and "adrenergic beta-3 agonists" were performed, along with searches for similar terms and the drugs of each type (e.g., tamsulosin, finasteride, imidafenacin, and mirabegron). We reviewed the abstracts of the results and included only clinical studies about the relevance of drugs to cognitive function. Similar terms were also used in the search to avoid the unintended exclusion of important similar articles from the search. To examine the possibility that the drug pharmacokinetics may affect cognitive function, the following keywords were searched in conjunction with the uro- logic drugs above: "blood-brain barrier," "permeability," and "pharmacokinetics." All animal studies related to the distribution of urologic medication in the central nervous system (CNS) and the potential for cognitive impairment were included.

\section{ALPHA BLOCKERS}

CNS-related side effects of alpha blockers, with the exception of dizziness, have not been reported in over 30 years since the market approval of the first alpha blocker; however, it is still unclear whether dizziness directly affects the brain or is a secondary effect of reduced blood pressure [17]. In particular, selective a1A-adrenergic receptor antagonists, such as silodosin and tamsulosin, were considered to have greater cardiovascular tolerability than other nonselective $\alpha$-adrenergic receptor antagonists [18].

However, a recent cohort study reported that the group taking tamsulosin had an increased incidence of dementia [19]. In this study, the authors retrospectively analyzed data from patients over 65 years of age with benign prostatic hyperplasia (BPH) from US Medicare records. Data from the tamsulosin cohort $(\mathrm{n}=253,136)$, no-BPH-medication cohort $(\mathrm{n}=180,926)$, doxazosin cohort $(n=28,581)$, terazosin cohort $(n=23,858)$, alfuzosin cohort $(n=17,934)$, dutasteride cohort $(n=34,027)$, and finasteride cohort $(n=38,767)$ were extracted. The median followup period for this study was 19.8 months. The risk of dementia was significantly higher in the tamsulosin cohort than in the no-BPH-medication cohort (hazard ratio [HR], 1.17) and significantly higher than that in the 5 cohorts for alternative $\mathrm{BPH}$ medication (HR, 1.11-1.26). The dose-response analysis also revealed a higher risk of dementia at higher doses in the tamsulosin cohort (HR, 1.12-1.49). The authors confirmed biological validity from studies that showed that $\alpha 1 \mathrm{~A}$-adrenoreceptors were reduced in the prefrontal cortex of patients with dementia and that tamsulosin suppressed centrally driven bulbospongiosus muscle contraction in a rat model $[20,21]$.

Overall, the results are quite impressive, and appeared to prove to be causal between tamsulosin and dementia. However, there are some questions that remain.

First, from a pharmacokinetic perspective, tamsulosin is a selective drug for the $11 \mathrm{~A}$-adrenoreceptor, and it's kind of systemic effect is thought to be less than the nonselective alpha blockers doxazosin, terazosin, and alfuzosin. In other words, other alpha blockers may bind to and affect a variety of subtypes of $\alpha$-adrenergic receptors, which may have a greater im- 
pact on the development of dementia than tamsulosin.

The second question is related to the blood-brain barrier (BBB) permeability. The drugs may affect cognitive function without penetrating the $\mathrm{BBB}$. In other words, if a drug can affect metabolism or regulation of hormones, it may have a secondary effect on the CNS. However, tamsulosin does not have peripheral actions that can adversely affect the brain. Thus, to cause dementia, tamsulosin must penetrate the $\mathrm{BBB}$ and act on the a $1 \mathrm{~A}$ adrenoreceptors in the brain [22]. Some studies reported that BBB permeability of tamsulosin was high [20,21], although other animal studies on the BBB penetration of alfuzosin, doxazosin, silodosin, and tamsulosin reported no or very low permeability of the BBB following intravenous or oral ingestion of alpha blockers [23-27]. In one animal study, tamsulosin enhanced memory function by activating N-methyl-D-aspartate receptor-mediated ion currents in the hippocampus [28]. If there is no biological validity, according to the Bradford Hill criteria, a proven association does not appear to indicate a causal relationship [29].

The third question was whether the follow-up period was too short. The associations reported by Duan et al. [19] spanned a median period of less than 2 years. This time period is too short to determine the occurrence of dementia and indicated an accelerated time to diagnosis [30].

In contrast, a recent retrospective cohort study reported that tamsulosin was not associated with the risk of dementia [31]. The authors retrospectively extracted information from the national health insurance service database and performed an analysis of patients over 70 years of age with BPH. In addition, the average age of patients enrolled in this study was higher than that in the study of Duan et al. [19] (76.1-76.7 years vs. 73.3-74.7 years). The median follow-up period was 56.4 months, which was relatively longer [19]. Six cohorts were extracted, and the number of patients in each cohort was as follows: tamsulosin ( $\mathrm{n}=33,568$ subjects), no-medication $(\mathrm{n}=$ $3,336)$, doxazosin $(n=7,012)$, terazosin $(n=9,443)$, and alfuzo$\sin (n=5,904)$. In their study, the incidence of dementia was higher in the terazosin group than the tamsulosin group (HR, 1.122). However, compared with the no-medication cohort, the BPH-medication cohort had a significantly lower risk of dementia (HR, 0.653-0.721). The authors of this study attributed their findings to the fact that the no-medication cohorts did not represent the general population distribution, rather than the fact that a-blockers lowered the risk of dementia. This large population-based study concluded that $\mathrm{BPH}$ drugs did not in- crease the risk of dementia, and the type of the drug.

Except for the recent debate on the association of dementia with tamsulosin, there appears to be no evidence that the remaining a-blockers (alfuzosin, doxazosin, terazosin, and silodosin) cause cognitive impairment. Some previous animal studies [23-25,27,28] have observed low drug binding in the rat cerebral cortex, suggesting that the drug is unlikely to penetrate the BBB. In addition, doxazosin had a neuroprotective effect in an in vitro model of Alzheimer disease [32]. However, terazosin was shown to cause cognitive impairment by decreasing of serotonin level [23]. However, in clinical studies, no association between dementia and cognitive impairment was observed [19,31].

In conclusion, there is little pharmacokinetic or no clinical evidence that alpha blockers promoted cognitive impairment (Table 1). Of course, alpha blockers may lower systemic blood pressure, but at least the possibility of cognitive impairment should not be a concern.

\section{5-ALPHA REDUCTASE INHIBITORS}

Finasteride and dutasteride are 5-alpha reductase inhibitors (5ARIs) used widely for the symptomatic treatment of $\mathrm{BPH}$ [17]. These 2 drugs are equally efficient, but finasteride inhibits only type 2 of 5 -alpha reductase and dutasteride inhibits both type 1 and 2 of 5-alpha reductase (5-AR) [33]. 5-ARIs are used in the symptomatic treatment of $\mathrm{BPH}$ as they inhibit the conversion of testosterone to dihydrotestosterone, reducing prostate volume [34].

Testosterone protects against age-related cognitive decline and dementia in men [35]. In other words, this result is pharmacokinetic evidence that 5-ARI can cause cognitive impairment and dementia. In a very recent animal study, 5-ARIs were reported to increase tau phosphorylation and alter dendritic morphology in the hippocampus of male mice, causing cognitive impairment. In this study, the activity of 5-AR was shown to be involved in the production of neurosteroids, and it was concluded that 5-AR plays an important role in neuroprotective effects [36]. In a population-based retrospective cohort study of male patients 66 years of age or older, 5-ARIs resulted in an increased incidence of self-injury and depression [37].

Contrary to the above results, several studies have reported that the incidence of dementia is not related to 5-ARIs. In a double-blind, placebo-controlled study, testosterone replacement therapy was not associated with improvement in age-re- 
Table 1. Literature review of alpha blockers

\begin{tabular}{|c|c|c|c|}
\hline $\begin{array}{l}\text { Agent } \\
\text { study }\end{array}$ & $\begin{array}{l}\text { BBB permeability } \\
\text { Type of study }\end{array}$ & $\begin{array}{l}\text { Cognitive } \\
\text { impairment }\end{array}$ & Strengths and weaknesses of the study \\
\hline Alfuzosin & Low & & \\
\hline Rouquier et al. [23] & Animal study & Less likely & In vivo, rat/intravenous injection/measured by using extracellular serotonin level \\
\hline Tae et al. [31] & Big data analysis & No & 51.9-Month follow-up/n=5,904/not associated with a risk of dementia with increased duration \\
\hline Doxazosin & Low & & \\
\hline Coelho et al. [32] & Animal study & No & In vivo, human neuroblastoma cell line/neuroprotective effects in patients with $\mathrm{AD}$ \\
\hline Tae et al. [31] & Population-based study & No & 51.9-Month follow-up/n=3,840/not associated with a risk of dementia \\
\hline Silodosin & Low & & \\
\hline Yamada et al. [25] & Animal study & Less likely & In vivo, rat/no specific binding in the cerebral cortex \\
\hline \multirow[t]{2}{*}{ Okura et al. [27] } & Animal study & Less likely & Ex vivo, rat/oral intake/lower distribution in cerebral cortex \\
\hline & No clinical trials & & \\
\hline Tamsulosin & Low & & \\
\hline Yamada et al. [26] & Animal study & Less likely & In vivo, rat/no specific binding in the cerebral cortex \\
\hline Kim et al. [28] & Animal study & No & In vivo, rat/medication period: 4 weeks/activating NMDA receptor-mediated ion currents \\
\hline Tae et al. [31] & Population-based study & No & 56.4-Month follow-up $/ \mathrm{n}=33,568 /$ not associated with a risk of dementia \\
\hline Duan et al. [19] & Population-based study & Yes & 19.8-Month follow-up/n =253,136/increased risk of dementia \\
\hline Terazosin & Low & & \\
\hline Tae et al. [31] & Population-based study & No & 51.9-Month follow-up/n=4,760/not associated with a risk of dementia \\
\hline Rouquier et al. [23] & Animal study & Intermediate & In vivo, rat/intravenous injection/measured by using extracellular serotonin level \\
\hline
\end{tabular}

Agents are sorted by alphabetical order.

BBB, blood-brain barrier; AD, Alzheimer disease; NMDA, N-methyl-D-Aspartate.

lated memory impairment in older patients [38]. In addition, a population-based study on the association of tamsulosin with the development of dementia reported that the administration of 5-ARIs was not associated with dementia [19].

In another study, the incidence of dementia was significantly increased in patients taking 5-ARIs. However, it has been reported that 5-ARIs and dementia are not causally linked because prolonged use reduced the risk of dementia [39].

In conclusion, recent results suggest that 5-ARIs are likely to cause affective disorders such as depression. In addition, although the results of clinical studies are positive, there is strong biological evidence that these drugs may affect cognitive function. Therefore, during the use of the 5-ARIs, it should be carefully checked for the development of mood disorders.

\section{ANTICHOLINERGICS}

Muscarinic receptors are important for high-level cognitive processes, such as memory and learning [40-43]. The adverse effects of anticholinergics, based on the known function of the muscarinic receptors in the CNS, are a serious concern [44-46].
With increasing age, the likelihood of developing LUTS from $\mathrm{OAB}$ increases $[5,6]$, which also increases the need for anticholinergics. However, the pharmacokinetic properties of anticholinergics itself described above are likely to cause cognitive impairment. So, it is necessary to classify the risks of each drug and to carefully select the treatment drug in older patients.

Oxybutynin has been used for the treatment of detrusor overactivity for over 40 years [47] and is reported to promote cognitive impairment in several clinical studies [48-50].

The CNS penetration of drugs is affected by 2 factors: the passive permeability of the BBB $[51,52]$ and the activity of efflux transporters in the brain tissue, such as P-glycoprotein (Pgp) $[53,54]$.

Oxybutynin had the largest passive permeability and the lowest efflux ratio by P-gp in the study of CNS penetration of $\mathrm{OAB}$ agents associated with cognitive impairment. In addition, the in vivo experiments in this study revealed that it had the highest cerebrospinal fluid (CSF): free plasma concentration ratio of 1.66 [55]. In vivo studies using positron emission tomography (PET) and autoradiography also showed that oxybutynin penetrates the $\mathrm{BBB}$ in a dose-dependent manner, reducing radioli- 
gand binding in rat and monkey brains [44,56,57]. These results provide clinical pharmacokinetic evidence that oxybutynin may affect cognitive impairment. Callegari et al. [55] reported the highest passive permeability for oxybutynin, followed by tolterodine, solifenacin, darifenacin, fesoterodine, and trospium. In particular, trospium is hydrophilic and showed little passive permeability. The efflux ratio by active transporters followed the order fesoterodine (13.7), darifenacin (4.0), solifenacin (1.3), and tolterodine (1.4). In vivo, the CSF:free plasma concentration ratios were in the order solifenacin (1.41), tolterodine $(0.16)$, darifenacin $(0.06)$, fesoterodine $(0.04)$, and trospium (0.004). Festoterodine and trospium showed the least CNS penetration. Darifenacin inhibits the contraction of human detrusor smooth muscle through only its antimuscarinic activity and not calcium channel antagonist activity $[58,59]$.

Several in vitro and animal studies confirming the brain occupancy of drugs by PET or autoradiography showed that darifenacin may be able to penetrate the BBB to some extent. However, no cognitive impairment was observed after systemic administration [55-57]. A randomized, double-blind, placebo clinical study of volunteers over 65 years of age found no effect on cognitive function after taking darifenacin [60].

Solifenacin has been shown to have a high affinity for M3 receptors mainly in in vitro studies of human recombinant muscarinic subtypes. Thus, solifenacin has been reported to selectively act on detrusor muscle contraction [61]. Solifenacin has been reported to have high passive permeability, low active transport efflux ratio in in vitro studies, high probability of CNS penetration [55], and greater effects on rat brain as the dose increased in in vivo studies [50]. However, some clinical studies showed no significant association with cognitive impairment $[50,62]$. Furthermore, one study reported that solifenacin could be safely used without aggravating cognitive impairment in patients with Alzheimer disease treated with donepezil [63].

Tolterodine is a nonselective anticholinergic drug used to treat $\mathrm{OAB}$ [64]. In vitro and radioligand binding studies have determined that tolterodine has a high potential for CNS penetration $[55,56]$. However, the results of a clinical study showed that the incidence of cognitive impairment was not significantly higher than that in the control group [65].

Trospium and fesoterodine were reported to have significantly lower CNS penetration than other anticholinergic agents in an in vitro study [55]. The relatively high molecular weight and low lipophilicity of fesoterodine, hydrophilic trospium, and the active metabolite of fesoterodine, 5-hydroxymethyl tolterodine, suggest that only very small amounts may cross the BBB [ 55 , $66,67]$. A study also reported the effects of taking fesoterodine for 12 weeks in older patients with urge incontinence and revealed no deterioration in cognitive function when subjects were assessed by the mean Mini-Mental Status Examination (MMSE) [68].

Imidafenacin was not likely to affect cognitive function because CNS penetration was not observed in a PET study in vivo [44,57]; this is supported by the absence of published clinical studies showing cognitive impairment. In addition, clinical studies using imidafenacin in patients with mild cognitive impairment (MCI) and Alzheimer disease had no effect on cognitive function [69].

Based on these reports, we classified anticholinergics into subcategories according to the effects on cognitive function as follows: class A (safe), low evidence for cognitive impairment based on pharmacokinetic and clinical papers; class B (debate), inadequate pharmacokinetic and clinical evidence on the occurrence of cognitive impairment; class $\mathrm{C}$ (cautious) pharmacokinetic and clinical evidence of drug-induced cognitive impairment. Accordingly, anticholinergics were classified (Table 2).

In conclusion, for class $\mathrm{C}$ drugs, it is necessary to limit the use in older patients. Class B drugs may cause cognitive impairment owing to their pharmacokinetics. However, there were no clinical studies to support these pharmacokinetic properties, or studies have shown contradictory results. Anticholinergic drugs in class B are suggested to be used with caution at low doses. For class A drugs, pharmacokinetic and clinical reports consistently show a weak association with cognitive dysfunction. Thus, they are thought to be safer than other anticholinergic drugs in older patients.

\section{BETA-3 AGONISTS}

There are 3 subtypes of beta-adrenoreceptors: beta-1, beta-2, and beta- 3 . Of these 3 subtypes, the beta- 3 adrenoreceptor is a $\mathrm{G}$ protein-binding receptor identified by genome replication in human cells [70].

When the beta-3 adrenoreceptor is activated, it mediates lipolysis in human brown and white fat cells and causes relaxation of smooth muscle in the gallbladder, stomach, small intestine, prostate, colon, and bladder [71,72]. It also controls memory, learning, and appetite [73]. Beta-3 agonists were reported to improve $\mathrm{OAB}$ in rat experimental models $[74,75]$, and recently mirabegron was reported as an alternative to anticholin- 
Table 2. Literature review of anticholinergics

\begin{tabular}{|c|c|c|c|}
\hline $\begin{array}{l}\text { Agent } \\
\text { Study }\end{array}$ & $\begin{array}{l}\text { Class } \\
\text { Type of study }\end{array}$ & $\begin{array}{l}\text { Cognitive } \\
\text { impairment }\end{array}$ & Strengths and weaknesses of the study \\
\hline Darifenacin & B & & \\
\hline Maruyama et al. [56] & Animal study & Less likely & Slight decrease in autoradiography/DDR: no \\
\hline Callegari et al. [55] & Animal study & Less likely & $\begin{array}{l}\text { BBB permeability based on physicochemical properties: significant/in vitro: high/in vitro: not } \\
\text { significant }\end{array}$ \\
\hline Yoshida et al. [57] & Animal study & No & In vivo PET study/potential adverse effects on the CNS: no \\
\hline Lipton et al. [60] & Clinical trial & No & $\mathrm{RCT} / \mathrm{n}=129 /$ mean age: 71.2 years of age/period: 14 days/no difference to control group/DDR: no \\
\hline Fesoterodine & A & & \\
\hline Dubeau et al. [68] & Clinical trial & No & $\begin{array}{l}\mathrm{RCT} / \mathrm{n}=562 \text {, patients } \geq 65 \text { years of age with urge incontinence/no deterioration in mean MMSE } \\
\text { scores }\end{array}$ \\
\hline Callegari et al. [55] & Animal study & Less likely & $\begin{array}{l}\text { BBB permeability based on physicochemical properties: significant/in vitro: moderate/in vitro: not } \\
\text { significant }\end{array}$ \\
\hline Imidafenacin & A & & \\
\hline Yoshida et al. [57] & Animal study & No & In vivo PET study/potential adverse effects on the CNS: no \\
\hline Yamamoto et al. [44] & Animal study & No & In vivo, monkey, $\mathrm{PET}$ study/mAChR occupancy: some extent/cognitive impairment: no \\
\hline Sakakibara et al. [69] & Clinical trial & No & $\begin{array}{l}\mathrm{N}=187 / \text { patients with } \mathrm{MCI} \text { or } \mathrm{AD} / \text { average daily dose: } 0.19 \mathrm{mg} / \text { adverse effect on cognitive } \\
\text { impairment: no }\end{array}$ \\
\hline Oxybutynin & $\mathrm{C}$ & & \\
\hline Callegari et al. [55] & Animal study & Yes & BBB permeability based on physicochemical properties: significant/In vivo: moderate/in vitro: high \\
\hline Maruyama et al. [56] & Animal study & Yes & In vivo autoradiography/DDR: yes \\
\hline Yoshida et al. [57] & Animal study & Yes & In vivo PET study/potential adverse effects on the CNS: yes \\
\hline Yamamoto et al. [44] & Animal study & Yes & In vivo $\mathrm{PET}$ study/occupied central $\mathrm{mAChR} /$ cognitive impairment: yes \\
\hline Katz et al. [48] & Clinical trial & Yes & $\mathrm{RCT} / \mathrm{n}=12 /$ healthy volunteer/daily doses: $5 \mathrm{mg}, 10 \mathrm{mg} /$ cognitive impairment: yes \\
\hline Esin et al. [65] & Clinical trial & No & Prospective study $/ \mathrm{n}=43 /$ patients with $\mathrm{OAB} \geq 65$ years of age $/$ no data about the $\mathrm{DDR}$ \\
\hline Wagg et al. [50] & Clinical trial & Yes & $\mathrm{RCT} / \mathrm{n}=26 /$ study subjects: $\geq 75$ years of age $\mathrm{MCI} /$ daily dose: $10 \mathrm{mg}$ \\
\hline Pietzko et al. [49] & Clinical trial & Yes & Phase I study/n=12/mean age: 26 years of age/daily dose: $20 \mathrm{mg} /$ change of EEG alpha range: yes \\
\hline Solifenacin & B & & \\
\hline Maruyama et al. [56] & Animal study & Possible & In vivo autoradiography/DDR: yes \\
\hline Callegari et al. [55] & Animal study & Possible & BBB permeability based on physicochemical properties: significant/In vitro: high/in vitro: significant \\
\hline Wesnes et al. [62] & Clinical trial & No & $\mathrm{n}=12 /$ healthy elderly (mean age: 69.1)/daily dose: $10 \mathrm{mg} / \mathrm{no}$ adverse effect on cognitive function \\
\hline Wagg et al. [50] & Clinical trial & No & $\mathrm{RCT} / \mathrm{n}=26$, MCI elderly ( $\geq 75$ years of age)/DD: $5 \mathrm{mg}$ /adverse effect on cognitive function: no \\
\hline Tolterodine & B & & \\
\hline Maruyama et al. [56] & Animal study & Yes & In vivo autoradiography/DDR: yes \\
\hline Callegari et al. [55] & Animal study & Yes & BBB permeability based on physicochemical properties: significant/in vitro: high/in vitro: significant \\
\hline Esin et al. [65] & Clinical trial & No & Prospective study/n $=21 /$ study subjects: patients with $O A B \geq 65$ years of age/DDR: No \\
\hline Trospium & A & & \\
\hline Pietzko et al. [49] & Clinical trial & No & $\begin{array}{l}\text { Phase I study } / \mathrm{n}=12 / \text { mean age: } 26 \text { years of age /daily dose: p.o. } 45 \mathrm{mg} \text {, i.v. } 1.2 \mathrm{mg} / \text { change in EEG } \\
\text { alpha range: no }\end{array}$ \\
\hline Callegari et al. [55] & Animal study & No & $\begin{array}{l}\text { BBB permeability based on physicochemical properties: not significant/In vivo: low/in vitro: } \\
\text { not significant }\end{array}$ \\
\hline Esin et al. [65] & Clinical trial & No & $\mathrm{n}=26 /$ study subjects: patients with $\mathrm{OAB} \geq 65$ years of age/no data about the DDR \\
\hline
\end{tabular}

Agents are sorted by alphabetical order.

DDR, dose-dependent response; BBB, blood-brain barrier; PET, positron emission tomography; CNS, central nervous system; RCT, randomized controlled trial; MMSE, Mini-Mental Status Examination; $\mathrm{mAChR}$, muscarinic cholinergic receptor; MCI: mild cognitive impairment; $\mathrm{AD}$, Alzheimer disease; OAB, overactive bladder; EEG, electroencephalography; p.o., per oral; i.v., intravenous. 
ergics in patients with $\mathrm{OAB}$, as the first selective beta- 3 agonist [76-78]. Several phase 2 and 3 studies have reported its high tolerability and efficacy [79-82]. Therefore, it has emerged as a new treatment option for patients with $\mathrm{OAB}$ who cannot take anticholinergic drugs owing to side effects such as dry mouth.

Mirabegron was approved by the U.S. Food and Drug Administration as the first beta-3 agonist in newest category of pharmaceutical treatment for OAB. In addition, it is confirmed by phase III clinical trial evaluating safety and efficacy in patients over the age of 65 years. However, there seems to be very little comment on cognition.

In very recently, a phase 4 placebo-controlled study (PILLAR; NCT02216214) about association between beta3-AR agonist medication and cognition, using Montreal Cognitive Assessment $(\mathrm{MoCA})$ test was conducted $[83,84]$. The MoCA test was validated in the setting of MCI. Additionally, the sensitivity of the MoCA for detecting MCI is $90 \%$, compared to $18 \%$ for other leading cognitive screening tools such as the MMSE [85]. In this PILLAR study, treatment with beta3-AR agonist, mirabegron for 12 weeks had no impact on cognitive function in older patients ( 65 years and older), as measured by the MoCA.

Although mirabegron has not yet been reported to cause cognitive impairment, it is a potential risk, and long-term studies are required.

\section{CONCLUSIONS}

In this review article, we examined the pharmacokinetic and clinical reports of the association between LUTS drugs and cognitive impairment. Alpha blockers are not expected to cause cognitive impairment. Although 5-ARIs have strong pharmacokinetic profiles that may suggest cognitive impairment, the clinical studies have shown that they are less prone to cause dementia. However, they may cause affective disorders such as depression. In the case of anticholinergic drugs, especially class C, the use of each drug should be considered carefully. Beta-3 agonists may replace anticholinergic agents for $\mathrm{OAB}$ treatment, but long-term studies are need.

\section{AUTHOR CONTRIBUTION STATEMENT}

\author{
- Conceptualization: $J H B$ \\ - Formal Analysis: YJK \\ - Investigation: $Y J K$ \\ - Methodology: YJK
}

- Project Administration: BST

-Writing-Original Draft: $Y J K$

-Writing-Review \& Editing: BST, JHB

\section{REFERENCES}

1. Prospective Population Estimates of Korea [Internet]. Daejeon (Korea): Statistics Korea; c2019 [cited 2019 Dec 16]. Available from: http://kosis.kr/statHtml/statHtml.do?orgId=101\&tblId=DT_ 1BPB002\&conn_path=I3.

2. Tae BS, Park TY, Jeon BJ, Chung H, Lee YH, Park JY, et al. Seasonal variation of overactive bladder symptoms in female patients. Int Neurourol J 2019;23:334-40.

3. Irwin DE, Milsom I, Hunskaar S, Reilly K, Kopp Z, Herschorn S, et al. Population-based survey of urinary incontinence, overactive bladder, and other lower urinary tract symptoms in five countries: results of the EPIC study. Eur Urol 2006;50:1306-14; discussion 14-5.

4. Kim KS, Jo JK, Lee JA, Choi BY, Moon HS. Do lifestyle factors affect lower urinary tract symptoms? Results from the Korean Community Health Survey. Int Neurourol J 2019;23:125-35.

5. Irwin DE, Milsom I, Kopp Z, Abrams P, Artibani W, Herschorn S. Prevalence, severity, and symptom bother of lower urinary tract symptoms among men in the EPIC study: impact of overactive bladder. Eur Urol 2009;56:14-20.

6. Stewart WF, Van Rooyen JB, Cundiff GW, Abrams P, Herzog AR, Corey R, et al. Prevalence and burden of overactive bladder in the United States. World J Urol 2003;20:327-36.

7. Kim HA, Shin JY, Kim MH, Park BJ. Prevalence and predictors of polypharmacy among Korean elderly. PLoS one 2014;9:e98043.

8. Cho YS. Treatment of prostate disease and cognitive problems. Int Neurourol J 2019;23:89-90.

9. Clegg A, Relton C, Young J, Witham M. Improving recruitment of older people to clinical trials: use of the cohort multiple randomised controlled trial design. Age Ageing 2015;44:547-50.

10. Shenoy P, Harugeri A. Elderly patients' participation in clinical trials. Perspect Clin Res 2015;6:184-9.

11. Leelakanok N, Holcombe AL, Lund BC, Gu X, Schweizer ML. Association between polypharmacy and death: a systematic review and meta-analysis. J Am Pharm Assoc (2003) 2017;57:729-38.e10.

12. Zia A, Kamaruzzaman SB, Tan MP. Polypharmacy and falls in older people: balancing evidence-based medicine against falls risk. Postgrad Med 2015;127:330-7.

13. Park HY, Park JW, Song HJ, Sohn HS, Kwon JW. The association between polypharmacy and dementia: a nested case-control study based on a 12-year longitudinal cohort database in South Korea. 
PLoS One 2017;12:e0169463.

14. Oelke M, Becher K, Castro-Diaz D, Chartier-Kastler E, Kirby M, Wagg A, et al. Appropriateness of oral drugs for long-term treatment of lower urinary tract symptoms in older persons: results of a systematic literature review and international consensus validation process (LUTS-FORTA 2014). Age Ageing 2015;44:745-55.

15. van den Akker M, Buntinx F, Metsemakers JF, Roos S, Knottnerus JA. Multimorbidity in general practice: prevalence, incidence, and determinants of co-occurring chronic and recurrent diseases. J Clin Epidemiol 1998;51:367-75.

16. Wehling M. Multimorbidity and polypharmacy: how to reduce the harmful drug load and yet add needed drugs in the elderly? Proposal of a new drug classification: fit for the aged. J Am Geriatr Soc 2009;57:560-1.

17. Muderrisoglu AE, Becher KF, Madersbacher S, Michel MC. Cognitive and mood side effects of lower urinary tract medication. Expert Opin Drug Saf 2019;18:915-23.

18. Oelke M, Gericke A, Michel MC. Cardiovascular and ocular safety of alphal-adrenoceptor antagonists in the treatment of male lower urinary tract symptoms. Expert Opin Drug Saf 2014;13:1187-97.

19. Duan Y, Grady JJ, Albertsen PC, Helen Wu Z. Tamsulosin and the risk of dementia in older men with benign prostatic hyperplasia. Pharmacoepidemiol Drug Saf 2018;27:340-8.

20. Giuliano F. Impact of medical treatments for benign prostatic hyperplasia on sexual function. BJU Int 2006;97 Suppl 2:34-8; discussion 44-5.

21. Szot P, White SS, Greenup JL, Leverenz JB, Peskind ER, Raskind MA. Changes in adrenoreceptors in the prefrontal cortex of subjects with dementia: evidence of compensatory changes. Neuroscience 2007;146:471-80.

22. Andrade C. How to read a research paper: an exercise in critical thinking in the context of an epidemiologic study on tamsulosin and the risk of dementia. J Clin Psychiatry 2018;79:18f12660.

23. Rouquier L, Claustre Y, Benavides J. Alpha 1-adrenoceptor antagonists differentially control serotonin release in the hippocampus and striatum: a microdialysis study. Eur J Pharmacol 1994;261:5964.

24. Hattori T, Sugaya K, Nishijima S, Kadekawa K, Ueda T, Yamamoto H. Emotional stress facilitates micturition reflex: possible inhibition by an al-adrenoceptor blocker in the conscious and anesthetized state. Int Neurourol J 2019;23:100-8.

25. Yamada S, Okura T, Kimura R. In vivo demonstration of alpha(1A)-adrenoceptor subtype selectivity of KMD-3213 in rat tissues. J Pharmacol Exp Ther 2001;296:160-7.

26. Yamada S, Ohkura T, Deguchi Y, Kimura R. In vivo measurement by $[3 \mathrm{H}]$ Tamsulosin of alphal adrenoceptors in rat tissues in relation to the pharmacokinetics. J Pharmacol Exp Ther 1999;289:157583.

27. Okura T, Yamada S, Abe Y, Kimura R. Selective and sustained occupancy of prostatic al-adrenoceptors by oral administration of KMD-3213 and its plasma concentration in rats. J Pharm Pharmacol 2002;54:975-82.

28. Kim CH, Ko IG, Kim SE, Shin MS, Kang YH, Cho JW, et al. Alphal-adrenoceptor antagonists improve memory by activating $\mathrm{N}$ methyl-D-aspartate-induced ion currents in the rat hippocampus. Int Neurourol J 2015;19:228-36.

29. Grimes DA, Schulz KF. Bias and causal associations in observational research. Lancet 2002;359:248-52.

30. Madersbacher S, Michel MC. Re: Tamsulosin and the risk of dementia in older men with benign prostatic hyperplasia. Eur Urol 2018;74:522-3.

31. Tae BS, Jeon BJ, Choi H, Cheon J, Park JY, Bae JH. a-Blocker and risk of dementia in patients with benign prostatic hyperplasia: a nationwide population based study using the national health insurance service database. J Urol 2019;202:362-8.

32. Coelho BP, Gaelzer MM, Dos Santos Petry F, Hoppe JB, Trindade VMT, Salbego CG, et al. Dual effect of doxazosin: anticancer activity on SH-SY5Y neuroblastoma cells and neuroprotection on an in vitro model of Alzheimer's disease. Neuroscience 2019;404:314-25.

33. Nickel JC, Gilling P, Tammela TL, Morrill B, Wilson TH, Rittmaster RS. Comparison of dutasteride and finasteride for treating benign prostatic hyperplasia: the Enlarged Prostate International Comparator Study (EPICS). BJU Int 2011;108:388-94.

34. Traish AM. 5alpha-reductases in human physiology: an unfolding story. Endocr Pract 2012;18:965-75.

35. Shin MS, Kim TW, Park SS, Ko IG, Kim CJ, Kim M, et al. Longterm surgical and chemical castration deteriorates memory function through downregulation of PKA/CREB/BDNF and c-Raf/ MEK/ERK pathways in hippocampus. Int Neurourol J 2019;23:11624.

36. Mendell AL, Creighton SD, Wilson HA, Jardine KH, Isaacs L, Winters $\mathrm{BD}$, et al. Inhibition of $5 a$ reductase impairs cognitive performance, alters dendritic morphology and increases tau phosphorylation in the hippocampus of male 3xTg-AD mice. Neuroscience 2020;429:185-202.

37. Welk B, McArthur E, Ordon M, Anderson KK, Hayward J, Dixon S. Association of suicidality and depression with 5alpha-reductase inhibitors. JAMA Intern Med 2017;177:683-91.

38. Resnick SM, Matsumoto AM, Stephens-Shields AJ, Ellenberg SS, Gill TM, Shumaker SA, et al. Testosterone treatment and cognitive 
function in older men with low testosterone and age-associated memory impairment. JAMA 2017;317:717-27.

39. Welk B, McArthur E, Ordon M, Morrow SA, Hayward J, Dixon S. The risk of dementia with the use of 5 alpha reductase inhibitors. J Neurol Sci 2017;379:109-11.

40. Corkin S. Acetylcholine, aging and Alzheimer's disease: implications for treatment. Trends Neurosci 1981;4:287-90.

41. Pavia J, De Ceballos M, de la Cuesta FS. Alzheimer's disease: relationship between muscarinic cholinergic receptors, $\beta$-amyloid and tau proteins. Fundam Clin Pharmacol 1998;12:473-81.

42. Quirion R, Aubert I, Lapchak P, Schaum R, Teolis S, Gauthier S, et al. Muscarinic receptor subtypes in human neurodegenerative disorders: focus on Alzheimer's disease. Trends Pharmacol Sci 1989;Suppl:80-4.

43. Avery EE, Baker LD, Asthana S. Potential role of muscarinic agonists in Alzheimer's disease. Drugs Aging 1997;11:450-9.

44. Yamamoto S, Maruyama S, Ito Y, Kawamata M, Nishiyama S, Ohba $\mathrm{H}$, et al. Effect of oxybutynin and imidafenacin on central muscarinic receptor occupancy and cognitive function: a monkey PET study with [11C](+) 3-MPB. Neuroimage 2011;58:1-9.

45. Risacher SL, McDonald BC, Tallman EF, West JD, Farlow MR, Unverzagt $\mathrm{FW}$, et al. Association between anticholinergic medication use and cognition, brain metabolism, and brain atrophy in cognitively normal older adults. JAMA Neurol 2016;73:721-32.

46. Ferreira-Vieira TH, Guimaraes IM, Silva FR, Ribeiro FM. Alzheimer's disease: targeting the cholinergic system. Curr Neuropharmacol 2016;14:101-15.

47. Jirschele K, Sand PK. Oxybutynin: past, present, and future. Int Urogynecol J 2013;24:595-604.

48. Katz IR, Sands LP, Bilker W, DiFilippo S, Boyce A, D’Angelo K. Identification of medications that cause cognitive impairment in older people: the case of oxybutynin chloride. J Am Geriatr Soc 1998;46:8-13.

49. Pietzko A, Dimpfel W, Schwantes U, Topfmeier P. Influences of trospium chloride and oxybutynin on quantitative eeg in healthyvolunteers. Eur J Clin Pharmacol 1994;47:337-43.

50. Wagg A, Dale M, Tretter R, Stow B, Compion G. Randomised, multicentre, placebo-controlled, double-blind crossover study investigating the effect of solifenacin and oxybutynin in elderly people with mild cognitive impairment: the SENIOR study. Eur Urol 2013;64:74-81.

51. van de Waterbeemd H, Camenisch G, Folkers G, Chretien JR, Raevsky OA. Estimation of blood-brain barrier crossing of drugs using molecular size and shape, and H-bonding descriptors. J Drug Target 1998;6:151-65.

52. Ertl P, Rohde B, Selzer P. Fast calculation of molecular polar surface area as a sum of fragment-based contributions and its application to the prediction of drug transport properties. J Med Chem 2000; 43:3714-7.

53. Eyal S, Hsiao P, Unadkat JD. Drug interactions at the blood-brain barrier: fact or fantasy? Pharmacol Ther 2009;123:80-104.

54. Liu X, Chen C, Smith BJ. Progress in brain penetration evaluation in drug discovery and development. J Pharmacol Exp Ther 2008;325:349-56.

55. Callegari E, Malhotra B, Bungay PJ, Webster R, Fenner KS, Kempshall S, et al. A comprehensive non-clinical evaluation of the CNS penetration potential of antimuscarinic agents for the treatment of overactive bladder. Br J Clin Pharmacol 2011;72:235-46.

56. Maruyama S, Tsukada H, Nishiyama S, Kakiuchi T, Fukumoto D, Oku N, et al. In vivo quantitative autoradiographic analysis of brain muscarinic receptor occupancy by antimuscarinic agents for overactive bladder treatment. J Pharmacol Exp Ther 2008;325:774-81.

57. Yoshida A, Maruyama S, Fukumoto D, Tsukada H, Ito Y, Yamada S. Noninvasive evaluation of brain muscarinic receptor occupancy of oxybutynin, darifenacin and imidafenacin in rats by positron emission tomography. Life Sci 2010;87:175-80.

58. Fetscher C, Fleichman M, Schmidt M, Krege S, Michel MC. M3 muscarinic receptors mediate contraction of human urinary bladder. Br J Pharmacol 2002;136:641-4.

59. Miyamae K, Yoshida M, Murakami S, Iwashita H, Ohtani M, Masunaga $\mathrm{K}$, et al. Pharmacological effects of darifenacin on human isolated urinary bladder. Pharmacology 2003;69:205-11.

60. Lipton RB, Kolodner K, Wesnes K. Assessment of cognitive function of the elderly population: effects of darifenacin. J Urol 2005;173:493-8.

61. Ikeda M, Nozawa K. Prevalence of overactive bladder and its related factors in Japanese patients with diabetes mellitus. Endocrine J 2015;62:847-54.

62. Wesnes KA, Edgar C, Tretter RN, Bolodeoku J. Exploratory pilot study assessing the risk of cognitive impairment or sedation in the elderly following single doses of solifenacin $10 \mathrm{mg}$. Expert Opin Drug Saf 2009;8:615-26.

63. Chase TN, Farlow MR, Clarence-Smith K. Donepezil plus solifenacin (CPC-201) treatment for Alzheimer's disease. Neurotherapeutics 2017;14:405-16.

64. Schwantes U, Topfmeier P. Importance of pharmacological and physicochemical properties for tolerance of antimuscarinic drugs in the treatment of detrusor instability and detrusor hyperreflexia-chances for improvement of therapy. Int J Clin Pharmacol Ther 1999;37:209-18.

65. Esin E, Ergen A, Cankurtaran M, Yavuz BB, Halil M, Ulger Z, et al. Influence of antimuscarinic therapy on cognitive functions and 
quality of life in geriatric patients treated for overactive bladder. Aging Mental Health 2015;19:217-23.

66.Cornu JN, Haab F. Traitements pharmacologiques de l'hyperactivité vésicale idiopathique: revue de la littérature [Pharmacological treatment of idiopathic overactive bladder: a literature review]. Prog Urol 2013;23:227-36. French.

67. Kerdraon J, Robain G, Jeandel C, Mongiat Artus P, Gamé X, Fatton $\mathrm{B}$, et al. Traitement anticholinergique de l'hyperactivité vésicale de la personne âgée et ses impacts sur la cognition. Revue de la littérature [Impact on cognitive function of anticholinergic drugs used for the treatment of overactive bladder in the elderly]. Prog Urol 2014;24:672-81. French.

68. Dubeau CE, Kraus SR, Griebling TL, Newman DK, Wyman JF, Johnson TM 2nd, et al. Effect of fesoterodine in vulnerable elderly subjects with urgency incontinence: a double-blind, placebo controlled trial. J Urol 2014;191:395-404.

69. Sakakibara R, Hamano H, Yagi H. Cognitive safety and overall tolerability of imidafenacin in clinical use: a long-term, open-label, post-marketing surveillance study. Low Urin Tract Symptoms 2014;6:138-44.

70. Emorine LJ, Marullo S, Briend-Sutren MM, Patey G, Tate K, Delavier-Klutchko C, et al. Molecular characterization of the human beta 3-adrenergic receptor. Science 1989;245:1118-21.

71. Berkowitz DE, Nardone NA, Smiley RM, Price DT, Kreutter DK, Fremeau RT, et al. Distribution of $\beta 3$-adrenoceptor mRNA in human tissues. Eur J Pharmacol 1995;289:223-8.

72. Fujimura T, Tamura K, Tsutsumi T, Yamamoto T, Nakamura K, Koibuchi $Y$, et al. Expression and possible functional role of the beta 3-adrenoceptor in human and rat detrusor muscle. J Urol 1999; 161:680-5.

73. Dehvari N, da Silva Junior ED, Bengtsson T, Hutchinson DS. Mirabegron: potential off target effects and uses beyond the bladder. $\mathrm{Br}$ J Pharmacol 2018;175:4072-82.

74. Kaidoh K, Igawa Y, Takeda H, Yamazaki Y, Akahane S, Miyata H, et al. Effects of selective beta2 and beta3-adrenoceptor agonists on detrusor hyperreflexia in conscious cerebral infarcted rats. J Urol 2002;168:1247-52.

75. Woods M, Carson N, Norton NW, Sheldon JH, Argentieri TM. Efficacy of the beta3-adrenergic receptor agonist CL-316243 on experimental bladder hyperreflexia and detrusor instability in the rat. J Urol 2001;166:1142-7.
76. Takasu T, Ukai M, Sato S, Matsui T, Nagase I, Maruyama T, et al. Effect of (R)-2-(2-aminothiazol-4-yl)-4'- [74] acetanilide (YM178), a novel selective beta3-adrenoceptor agonist, on bladder function. J Pharmacol Exp Ther 2007;321:642-7.

77. Chapple CR, Siddiqui E. Mirabegron for the treatment of overactive bladder: a review of efficacy, safety and tolerability with a focus on male, elderly and antimuscarinic poor-responder populations, and patients with OAB in Asia. Expert Rev Clin Pharmacol 2017; 10:131-51.

78. Chapple CR, Cardozo L, Nitti VW, Siddiqui E, Michel MC. Mirabegron in overactive bladder: a review of efficacy, safety, and tolerability. Neurourol Urodynam 2014;33:17-30.

79. Chapple CR, Dvorak V, Radziszewski P, Van Kerrebroeck P, Wyndaele JJ, Bosman B, et al. A phase II dose-ranging study of mirabegron in patients with overactive bladder. Int Urogynecol J 2013;24:1447-58.

80. Herschorn S, Barkin J, Castro-Diaz D, Frankel JM, Espuna-Pons M, Gousse AE, et al. A phase III, randomized, double-blind, parallelgroup, placebo-controlled, multicentre study to assess the efficacy and safety of the $\beta 3$ adrenoceptor agonist, mirabegron, in patients with symptoms of overactive bladder. Urology 2013;82:313-20.

81. Chapple CR, Amarenco G, López Aramburu MA, Everaert K, Liehne J, Lucas M, et al. A proof-of-concept study: mirabegron, a new therapy for overactive bladder. Neurourol Urodynam 2013; 32:1116-22.

82. Nitti VW, Auerbach S, Martin N, Calhoun A, Lee M, Herschorn S. Results of a randomized phase III trial of mirabegron in patients with overactive bladder. J Urol 2013;189:1388-95.

83. Griebling TL, Campbell NL, Mangel J, Staskin D, Herschorn S, Elsouda $\mathrm{D}$, et al. Effect of mirabegron on cognitive function in elderly patients with overactive bladder: MoCA results from a phase 4 randomized, placebo-controlled study (PILLAR). BMC Geriatr 2020;20:109.

84. Wagg A, Staskin D, Engel E, Herschorn S, Kristy RM, Schermer CR. Efficacy, safety, and tolerability of mirabegron in patients aged $>/=65$ yr with overactive bladder wet: a phase IV, double-blind, randomised, placebo-controlled study (PILLAR). Eur Urol 2020; 77:211-20.

85. Nasreddine ZS, Phillips NA, Bedirian V, Charbonneau S, Whitehead V, Collin I, et al. The Montreal Cognitive Assessment, MoCA: a brief screening tool for mild cognitive impairment. J Am Geriatr Soc 2005;53:695-9. 